\title{
PAX 8 expression in non-neoplastic tissues, primary tumors, and metastatic tumors: a comprehensive immunohistochemical study
}

\author{
Ayhan Ozcan ${ }^{1,2,3}$, Steven S Shen ${ }^{1,2,4}$, Candice Hamilton ${ }^{1}$, Kundu Anjana ${ }^{1}$, Donna Coffey ${ }^{1,2,4}$, \\ Bhuvaneswari Krishnan ${ }^{5}$ and Luan D Truong ${ }^{1,2,4,5}$
}

${ }^{1}$ Departments of Pathology, The Methodist Hospital, Houston, TX, USA; ${ }^{2}$ Weill Medical of College of Cornell University, New York, NY, USA; ${ }^{3}$ School of Medicine, Gülhane Military Medical Academy, Ankara, Turkey; ${ }^{4}$ The Methodist Hospital Research Institute, Houston, TX, USA and ${ }^{5}$ Baylor College of Medicine, Houston, TX, USA

PAX 8 is a transcription factor that is essential for embryonic development of the kidney, Müllerian organs, and thyroid. It may also have a role in tumor development in these organs. The diagnostic utility of PAX 8 has not been comprehensively studied. Formalin-fixed, paraffin-embedded tissue samples for non-neoplastic tissues $(n=1601)$, primary neoplasms $(n=933)$, and metastatic neoplasms $(n=496)$ were subjected to PAX 8 immunostain. In non-neoplastic tissues, PAX 8 was consistently noted in glomerular parietal epithelial cells, renal collecting ductal cells, atrophic renal tubular epithelial cells regardless of nephronic segments, and epithelial cells of the endocervix, endometrium, fallopian tube, seminal vesicle, epidydimis, thyroid, pancreatic islet cells, and lymphoid cells. PAX 8 was not seen in the rest of the tissue samples. In primary neoplasms, PAX 8 was expressed by 194 of $240(89 \%)$ renal cell neoplasms, by 238 of $267(89 \%)$ Müllerian-type neoplasms, by 65 of $65(100 \%)$ thyroid follicular cell neoplasms, by 8 of $8(100 \%)$ nephrogenic adenomas, and by 17 of $17(100 \%)$ lymphomas. Weak focal staining was noted in 5 of $12(42 \%)$ cases of parathyroid hyperplasia/adenoma and in 6 of $17(35 \%)$ well-differentiated neuroendocrine tumors of the pancreas. PAX 8 was not seen in other neoplasms. In metastatic neoplasms, PAX 8 was expressed by 90 of $102(88 \%)$ metastatic renal cell carcinomas, by 57 of 63 metastatic Müllerian tumors (90\%), and by 6 of 6 metastatic papillary thyroid carcinomas (100\%). There was also weak focal staining for 1 of 15 metastatic small cell carcinomas and for 1 of 9 metastatic well-differentiated neuroendocrine carcinomas. PAX 8 was not seen in other metastatic neoplasms. It can be successfully identified in routinely processed tissue samples, and its expression is mostly nuclear. PAX 8 expression in nonneoplastic mature tissues is limited to the organs, the embryonic development of which depends on this transcription factor. This tissue/cell-specific expression is maintained during both neoplastic transformation and metastasis. PAX 8 is a sensitive and specific marker for tumors of renal, Müllerian, or thyroid origin in both primary and metastatic sites.

Modern Pathology (2011) 24, 751-764; doi:10.1038/modpathol.2011.3; published online 11 February 2011

Keywords: female genital tract; immunohistochemistry; kidney; neoplasm; pancreas; PAX8; thyroid

Transcription factors are proteins that are localized to the cell nuclei and help control the transcription of specific genes. ${ }^{1,2} P A X 8$ belongs to the paired box gene family consisting of nine members, ie, $P A X 1$ through $P A X 9$, each of which encodes a transcrip-

Correspondence: Dr L Truong, MD, Department of Pathology, MS 205, The Methodist Hospital, 6565 Fannin Street, Houston, TX 77030, USA.

E-mail: ltruong@tmhs.org

Received 28 June 2010; revised 19 October 2010; accepted 20

October 2010; published online 11 February 2011 tion factor. These transcription factors are expressed in an orderly manner during fetal development., ${ }^{1,2}$ They have a critical role in the formation of tissues and organs during embryonic development and are also crucial for maintaining the normal function of certain cells after birth. ${ }^{1,2}$ As a transcription factor, PAX 8 is known to control the development of the central nervous system, eye, kidney, thyroid gland, organs deriving from the mesonephric (wolffian) duct, and those related to the Müllerian duct. ${ }^{3-9}$

Transcription factors are identified in the nuclei of cell types that are under their developmental control 
during organogenesis, but they often disappear in mature tissues. ${ }^{1,2}$ However, these transcription factors may re-express in an organ-specific manner during neoplastic transformation. ${ }^{10}$ For example, PAX 8 is abundantly expressed by renal blastema cells during nephrogenesis, and then is noted in only a few renal parenchymal cells in the mature kidney, but is identified again in renal cell carcinoma. ${ }^{1,2,5-11}$ Therefore, the tissue expression of transcription factor has been used as a specific marker for tumor diagnosis.

A few limited studies have identified PAX 8 in neoplasms of the organs the embryogenesis of which is under control of this transcription factor, including thyroid follicular neoplasm, ${ }^{12-15}$ renal cell carcinoma, ${ }^{11,16}$ nephrogenic adenoma, ${ }^{17}$ and ovarian carcinoma. ${ }^{18-20}$ Confirmation of PAX 8 as a sensitive marker for these tumor types is required. Furthermore, the utilization of PAX 8 as a diagnostic tumor marker is predicated on several considerations including the knowledge on the expression of PAX 8 in normal/reactive tissues, primary neoplasms, and their metastatic congeners across the spectrum of tissue types. These considerations underlie the focus of this study.

\section{Materials and methods}

This retrospective study included 1601 samples of normal or reactive tissue types (Table 1), 933 primary neoplasms including 240 from the kidney, 247 from the female genital tract, 73 from the thyroid, and 17 well-differentiated neuroendocrine tumors of the pancreas (Table 2), as well as 496 metastatic neoplasms, including 102 of the renal primary, 63 of the female genital tract primary, 6 from the thyroid, and the rest from various tissue/ organ origins (Table 3). Although preference was given to tumor types with expected PAX 8 expression, ie, thyroid, renal, and Müllerian origins, many other tumor types were also adequately represented for a meaningful observation. Except for 2 tissue arrays consisting of 45 endometrial tumors and 36 ovarian tumors, respectively, whole-tissue sections from 1 tissue blocks from other tissues or tumors were used for immunostain.

Tissue sections were subjected to deparaffinization, hydration, and endogenous peroxidase blocking. Antigen retrieval was achieved by Dako Target Retrieval Solution, pH 6 (Dako, Carpinteria, CA) in a pressure cooker set at $95 \mathrm{C}$ for $22 \mathrm{~min}$, followed by gradual cooling for $20 \mathrm{~min}$. The tissue sections were incubated for $30 \mathrm{~min}$ at room temperature with an anti-PAX 8 polyclonal antibody (ProteinTech Group, Chicago, IL; dilution 1:50). Detection of the staining reaction was achieved by an enzymeconjugated polymer complex adapted for automatic stainers from Ventana (Ventana Medical Systems, Tucson, AZ).

Positive controls included renal carcinoma tissues and lymphoid tissues, which often also served as

Table 1 PAX 8 expression in normal or non-neoplastic tissues

Renal tubular cells

Glomeruli

Ovarian surface epithelial cells

Ovarian epithelial inclusion cyst

Fallopian tubal epithelial cells

Endocervical epithelial cells

Endometrial epithelial cells

Adenomyosis/endometriosis

Endosalpingiosis

Ovarian stromal cells

Exocervical squamous cells

Endometrial stromal cells

Cervical stromal cells

Seminal vesicle epithelial cells

Epidydimal epithelial cells

Seminiferous tubule cells

Sertoli cells

Leydig cells

Prostatic epithelial cells

Regenerative bile duct cells

Hepatocytes

Native bile duct cells

Parathyroid epithelial cells

Thyroid epithelial cells

Brain cells

Urothelial cells

Lymphoid cells

Breast epithelial cells

Pulmonary epithelial cells

Adrenal cortical cells

Adrenal medullary cells

Gastrointestinal epithelial cells

Pancreatic acinar cells

Pancreatic ductal cells

Pancreatic islet cells

Salivary gland parenchymal cells

Squamous epithelial cells

Mesothelial cells

Muscle cells (smooth, skeletal, and cardiac)

Connective tissue cells (including fibroblasts) ${ }^{\mathrm{c}}$

Total

${ }^{\mathrm{a}}$ Focal segmental staining of parietal epithelial cell nuclei only.

${ }^{\mathrm{b}}$ Cerebellar cell nuclei.

${ }^{\mathrm{C}}$ Connective tissue cell staining is evaluated in every tissue section.

built-in controls as lymphoid cells are often seen in the evaluated tissue sections. Mesenchymal or epithelial cells in the evaluated tissue sections served as negative controls. For each case, the nuclear staining pattern, staining intensity $(0=$ no stain, $1+=$ unequivocal but weak, $2+=$ moderate, $3+=$ strong), and staining extent (estimated percentage of stained cells) were recorded.

\section{Results}

\section{General Features}

PAX 8 was successfully detected in routinely processed tissues with appropriate positive and negative controls. The stain was almost exclusively nuclear, with no or negligible cytoplasmic expression. 
Table 2 PAX 8 expression in primary neoplasms

\begin{tabular}{|c|c|c|}
\hline Organ & Diagnoses & Positive/total cases (\%) \\
\hline \multirow[t]{17}{*}{ Kidney } & RCC, clear cell & 90/95 (95\%) \\
\hline & RCC, papillary ${ }^{\mathrm{a}}$ & $38 / 38(100 \%)$ \\
\hline & RCC, chromophobe & $22 / 25(88 \%)$ \\
\hline & RCC, collecting duct & $5 / 7(71 \%)$ \\
\hline & RCC, sarcomatoid & $4 / 9(44 \%)$ \\
\hline & RCC, rhabdoid & $0 / 4(0 \%)$ \\
\hline & RCC, mucinous tubular & $6 / 6(100 \%)$ \\
\hline & RCC, ACK-related & $8 / 8(100 \%)$ \\
\hline & RCC, translocation & $1 / 2(50 \%)$ \\
\hline & RCC, tubulocystic & $1 / 1(100 \%)$ \\
\hline & Metanephric neoplasms & $3 / 3(100 \%)$ \\
\hline & Mixed epithelial and stromal tumors & $4 / 4(100 \%)$ \\
\hline & Cystic nephroma & $4 / 4(100 \%)$ \\
\hline & Urothelial carcinoma & $0 / 13(0 \%)$ \\
\hline & Oncocytoma & $8 / 13(61 \%)$ \\
\hline & Angiomyolipoma & $0 / 8(0 \%)$ \\
\hline & Total & $194 / 240(89 \%)$ \\
\hline \multirow[t]{10}{*}{ Female genital tract $\mathrm{t}^{\mathrm{b}}$} & Endometrioid carcinoma & $72 / 77(93 \%)$ \\
\hline & Endometrial polyp & $8 / 8(100 \%)$ \\
\hline & Serous carcinoma & 101/102 (99\%) \\
\hline & Serous adenoma/borderline tumors & $22 / 23(95 \%)$ \\
\hline & Mucinous carcinoma & $4 / 10(40 \%)$ \\
\hline & Mucinous adenoma/borderline tumors & $3 / 13(23 \%)$ \\
\hline & Clear cell carcinoma & $16 / 16(100 \%)$ \\
\hline & Other types $^{\mathrm{c}}$ & $12 / 18(66 \%)$ \\
\hline & Cervical squamous cell carcinoma & $0 / 9(0 \%)$ \\
\hline & Total & $238 / 267(89 \%)$ \\
\hline \multirow[t]{3}{*}{ Thyroid } & Follicular and papillary neoplasms & $65 / 65(100 \%)$ \\
\hline & Medullary carcinoma & $0 / 8(0 \%)$ \\
\hline & Total & $65 / 73(89 \%)$ \\
\hline \multirow[t]{2}{*}{ Urinary bladder } & Urothelial neoplasm/dysplasia & $0 / 20(0 \%)$ \\
\hline & Nephrogenic adenoma & $8 / 8(100 \%)$ \\
\hline Hematopoietic organs & Lymphoma, all types & $17 / 17(100 \%)$ \\
\hline Parathyroid & Parathyroid adenoma/hyperplasia & $5 / 12(42 \%)$ \\
\hline \multirow[t]{3}{*}{ Liver } & Hepatocellular neoplasms & $0 / 24(0 \%)$ \\
\hline & Bile duct neoplasms & $0 / 16(0 \%)$ \\
\hline & Hepatoblastoma & $0 / 2(0 \%)$ \\
\hline \multirow[t]{3}{*}{ Lung } & Squamous cell carcinoma & $0 / 4(0 \%)$ \\
\hline & Adenocarcinoma & $0 / 7(0 \%)$ \\
\hline & Small cell carcinoma & $0 / 12(0 \%)$ \\
\hline \multirow[t]{2}{*}{ Breast } & Carcinoma, all types & $0 / 73(0 \%)$ \\
\hline & Fibroadenoma and phylloides tumor & $0 / 6(0 \%)$ \\
\hline \multirow[t]{2}{*}{ Gastrointestinal tract } & Adenocarcinoma & $0 / 25(0 \%)$ \\
\hline & Neuroendocrine carcinoma & $0 / 3(0 \%)$ \\
\hline \multirow[t]{2}{*}{ Pancreas } & Adenocarcinoma & $0 / 14(0 \%)$ \\
\hline & Islet cell tumor, well differentiated & $6 / 17(35 \%)$ \\
\hline Prostate & Adenocarcinoma & $0 / 40(0 \%)$ \\
\hline \multirow[t]{2}{*}{ Skin } & Melanoma & $0 / 6(0 \%)$ \\
\hline & Squamous cell carcinoma & $0 / 4(0 \%)$ \\
\hline Larynx & Squamous cell carcinoma & $0 / 3(0 \%)$ \\
\hline Thymus & Carcinoma & $0 / 3(0 \%)$ \\
\hline \multirow{2}{*}{ Adrenal } & Adrenal cortical neoplasms & $0 / 21(0 \%)$ \\
\hline & Pheochromocytoma & $0 / 3(0 \%)$ \\
\hline Salivary gland & Pleomorphic adenoma & $0 / 4(0 \%)$ \\
\hline Testis & Germcell tumors & $0 / 12(0 \%)$ \\
\hline Mesenchyme & Mesenchymal tumors & $0 / 26(0 \%)$ \\
\hline Pleura & Mesothelioma & $0 / 2(0 \%)$ \\
\hline Total & & $533 / 933(57 \%)$ \\
\hline
\end{tabular}

${ }^{\mathrm{a}}$ Including type 1, type 2, clear cell, and oncocytic variants.

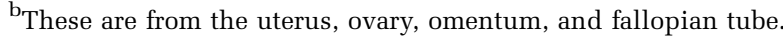

${ }^{\mathrm{C}}$ Undifferentiated, squamous, urothelial, and Brenner tumors.

\section{Normal/Reactive Tissues}

A distinctive tissue-specific expression of PAX 8 was noted among the 1601 non-neoplastic tissue samples (Table 1 and Figure 1). In the normal kidney, focal segmental staining of glomerular parietal epithelial cells and diffuse staining of collecting duct epithelial cells were noted (Figure 1a), but other cells were negative. In contrast, atrophic renal tubules, regardless of nephronic 
segment derivation, including those often seen at the periphery of most space-occupying renal lesions, showed strong PAX 8 expression (Figure 1b). In the female genital tract, strong and diffuse nuclear staining was noted in the epithelial cells of the endocervix and the endometrium in all cases (Figure 1c and d). Although the fallopian tube epithelium shows constant staining, only basal and secretory cells, but not ciliated cells, were stained (Figure 1e). Five out of eight samples of ovarian surface epithelial cells showed staining, and the staining was focal. Endometriosis, endosalpingiosis, paraovarian Müllerian embryonic rests, paratubal cysts, and ovarian epithelial inclusions were uniformly positive. In the male genital tract, strong and diffuse staining was noted in seminal vesicles and epididymis (Figure 1f) in all specimens, but not in germ cells, Leydig cells, or Sertoli cells (Figure 1g). Lymphocytes in each of the 65 lymphoid tissue samples were positive, in which positive cells were noted mostly in lymphoid follicles with or without germinal center and in much fewer lymphocytes in other areas of the lymph nodes (Figure 1h). Strong and diffuse staining of thyroid follicular epithelial cells was noted in each of the 80 samples (Figure 1i). Although the native bile duct epithelium was negative, unequivocal PAX 8 expression was noted in some regenerative ductules in 4 of $35(11 \%)$ liver samples. Focal or diffuse staining was noted in islet cells in 19 of $27(70 \%)$ pancreatic tissue samples. Focal staining was seen in 5 of $14(35 \%)$ parathyroid tissue samples (Figure 1j and k). PAX 8 was not seen in other tissue types including stromal cells of the organs, the epithelial components of which uniformly expressed PAX 8.

\section{Primary Neoplasms}

PAX 8 staining was noted in 533 of 933 (57\%) tumors in a manner that recapitulated its expression in non-neoplastic tissues (Table 2, Figures 2 and 3).

Table 3 PAX 8 expression in metastatic neoplasms

\begin{tabular}{|c|c|c|c|}
\hline & Primary site & Metastatic sites & $\begin{array}{l}\text { Positive/total } \\
\text { cases (\%) }\end{array}$ \\
\hline \multirow[t]{6}{*}{ Renal cell carcinoma } & Kidney, all histological types & $\begin{array}{l}\text { Lung, node, liver, brain, pancreas, } \\
\text { bone, pleura, skin, soft tissue, spleen }\end{array}$ & $90 / 102(88 \%)$ \\
\hline & Clear cell & & $75 / 80(93 \%)$ \\
\hline & Papillary & & $10 / 10(100 \%)$ \\
\hline & Collecting duct & & $4 / 5(80 \%)$ \\
\hline & Chromophobe & & $1 / 1(100 \%)$ \\
\hline & Sarcomatoid & & $0 / 6(0 \%)$ \\
\hline All Müllerian tumors & & & $57 / 63(90 \%)$ \\
\hline Endometrioid carcinoma & Uterus & Node, omentum, liver & $7 / 7(100 \%)$ \\
\hline Undifferentiated carcinoma & Ovary & Omentum & $4 / 8(50 \%)$ \\
\hline Serous carcinoma & Ovary & Omentum, pleura, node, liver & $44 / 46(95 \%)$ \\
\hline Clear cell carcinoma & Ovary & Lung & $2 / 2(100 \%)$ \\
\hline Neuroendocrine carcinoma & Pancreas, GI tract & Node, liver & $1 / 9(11 \%)^{a}$ \\
\hline Small cell carcinoma & Lung & Node, bone, liver & $1 / 15(7 \%)^{\mathrm{a}}$ \\
\hline Thyroid papillary carcinoma & Thyroid & Node & $6 / 6(100 \%)$ \\
\hline \multirow[t]{8}{*}{ Adenocarcinoma } & Stomach & Node, small bowel, omentum, liver & $0 / 5(0 \%)$ \\
\hline & Prostate & Node, bone, testis, brain, seminal vesicle & $0 / 44(0 \%)$ \\
\hline & Colon & Node, liver, brain, lung, bladder, kidney & $0 / 39(0 \%)$ \\
\hline & Appendix & Peritoneum & $0 / 1(0 \%)$ \\
\hline & Breast & Node & $0 / 62(0 \%)$ \\
\hline & Pancreas & Liver, kidney, omentum & $0 / 8(0 \%)$ \\
\hline & Lung & Bone, brain, kidney, liver & $0 / 9(0 \%)$ \\
\hline & Bile duct & Omentum, node & $0 / 6(0 \%)$ \\
\hline Squamous cell carcinoma & Lung & Bowel, brain, node & $0 / 6(0 \%)$ \\
\hline Urothelial carcinoma & Bladder & Liver, lung, node, bone & $0 / 10(0 \%)$ \\
\hline Hepatocellular carcinoma & Liver & Node & $0 / 1(0 \%)$ \\
\hline Malignant melanoma & Skin & Node, liver & $0 / 6(0 \%)$ \\
\hline Adrenal cortical carcinoma & Adrenal cortex & Liver & $0 / 2(0 \%)$ \\
\hline Total & & & $245 / 496(49 \%)$ \\
\hline
\end{tabular}

Node, lymph node.

${ }^{\mathrm{a}}$ Less than $5 \%$ of cell nuclei were stained.

Figure 1 Normal/reactive tissues. (a) Normal kidney: PAX 8 expression limited to the nuclei of distal nephron tubular segments and parietal epithelial cells. (b) Diffuse PAX 8 expression in all atrophic tubules throughout the nephron. (c) Secretory endometrium. (d) PAX 8 expression in endocervical columnar cells, but not in exocervical squamous epithelial cells (upper). (e) Fallopian tube: PAX 8 expression in secretory and basal cells, but not in ciliated cells. (f) Normal testis: PAX 8 expression in efferent ducts (left) and epididymis (right). (g) Normal testis: PAX 8 expression in rete testis (upper right), but not in seminiferous tubules (lower left). (h) Lymph node: PAX 8 expression in lymphoid follicles and few cells of the interfollicular areas. (i) Diffuse staining of normal thyroid follicular cells. (j, k) The regenerative bile duct (panel $\mathbf{j}$ ) is focally stained for PAX 8 (panel $\mathbf{k})(\times 400$ for panel $\mathbf{i}$; $\times 200$ for all other panels). 
Among 194 renal neoplasms, PAX 8 was noted in the vast majority of renal cell carcinomas regardless of histological subtypes (Figure 2a-l), including collecting duct renal cell carcinomas (71-100\%). Noticeably, 4 of 9 (44\%) sarcomatoid renal cell carcinomas were positive. PAX 8 was noted in the
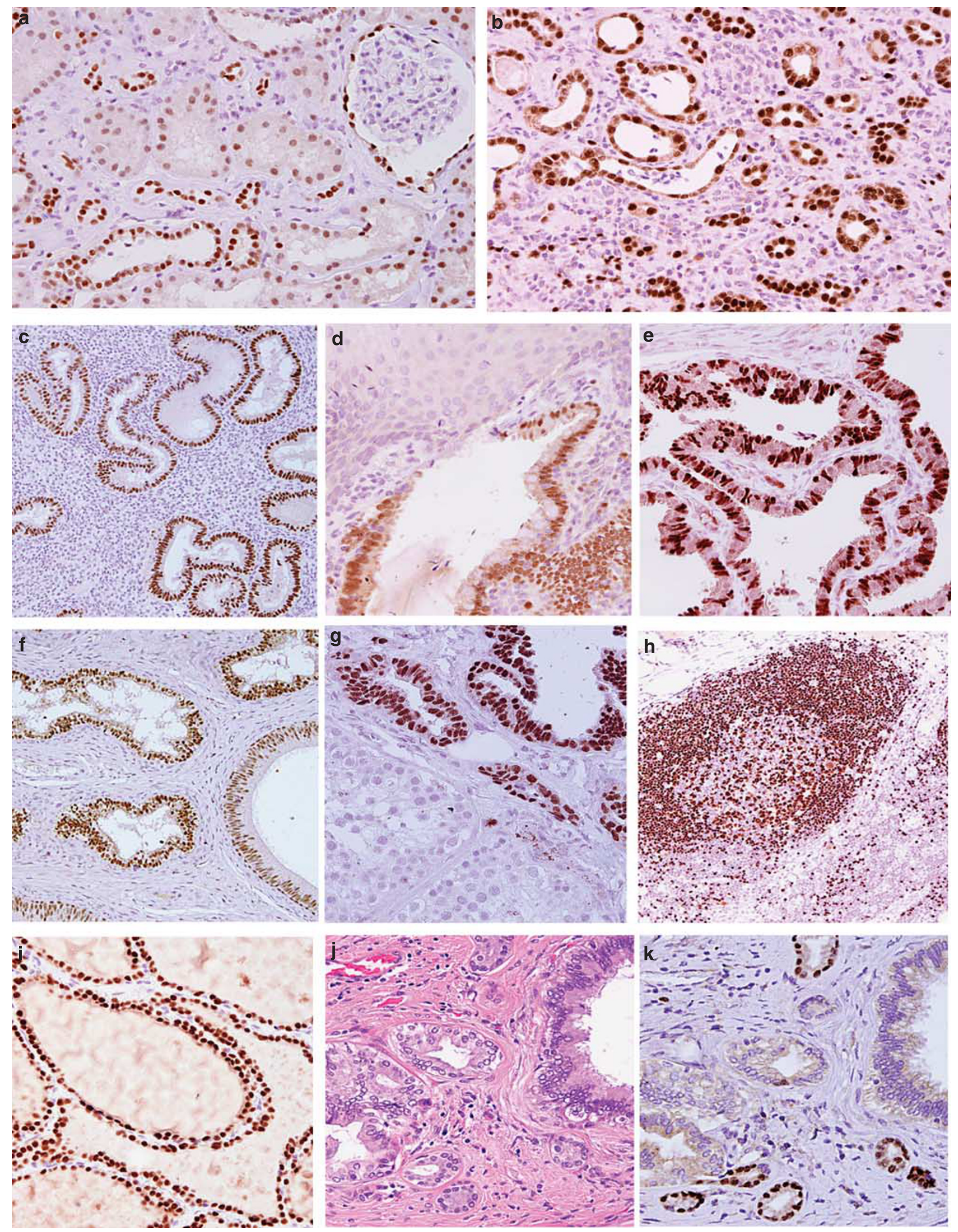


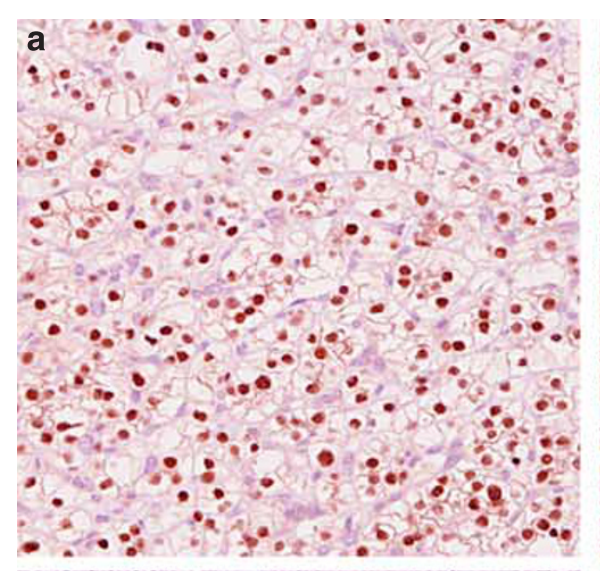

d.

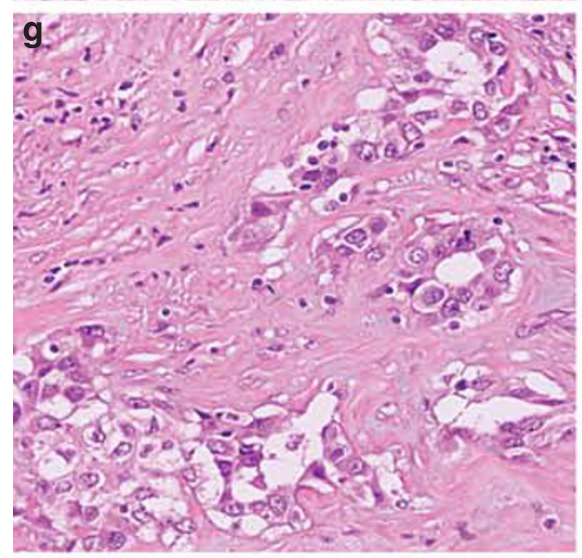

1250 on

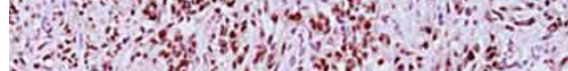

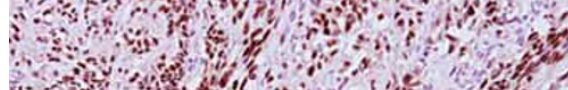

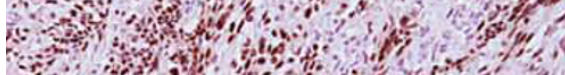

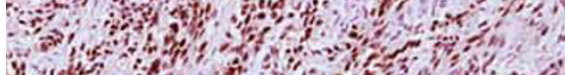

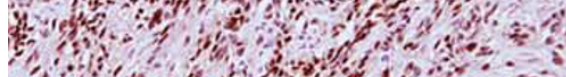

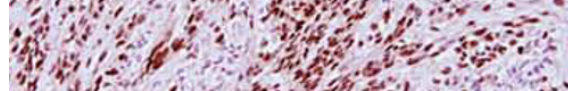
(1) 14, की

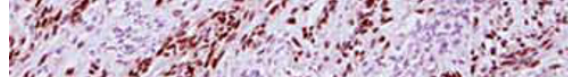

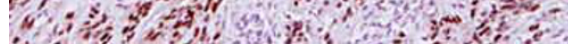
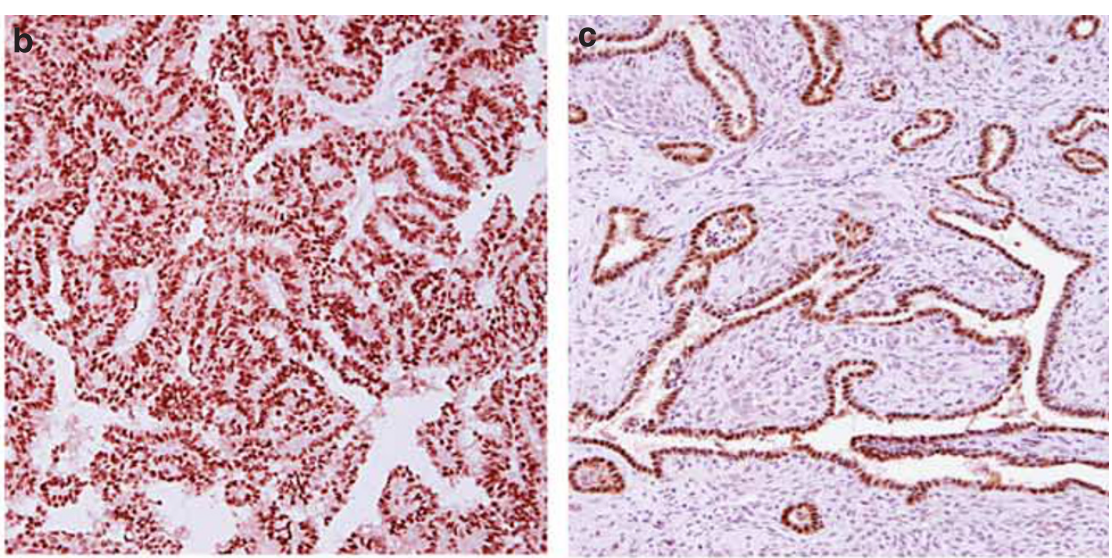

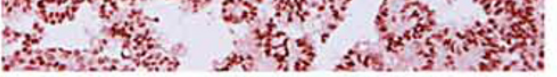
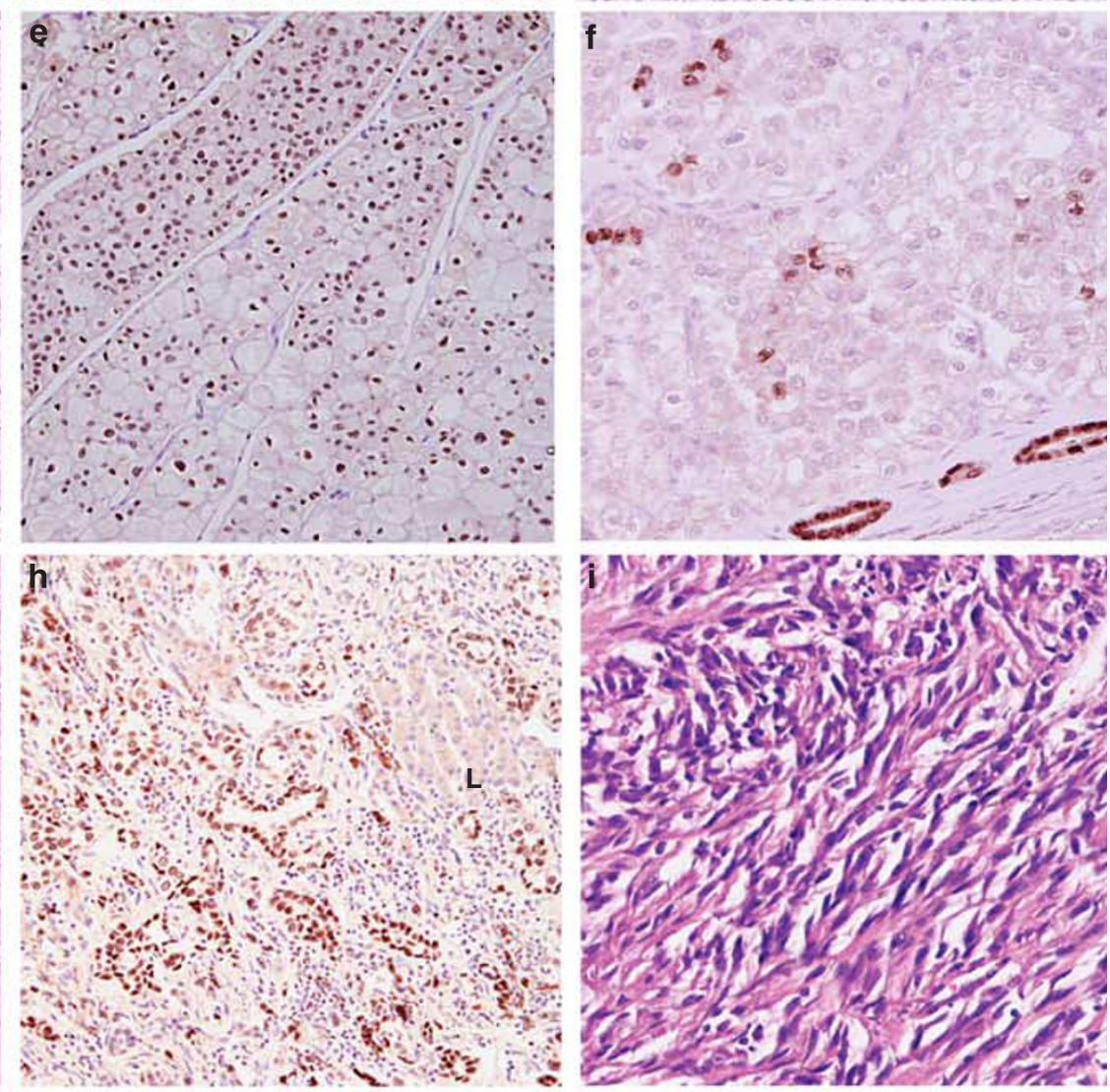

7 Mory
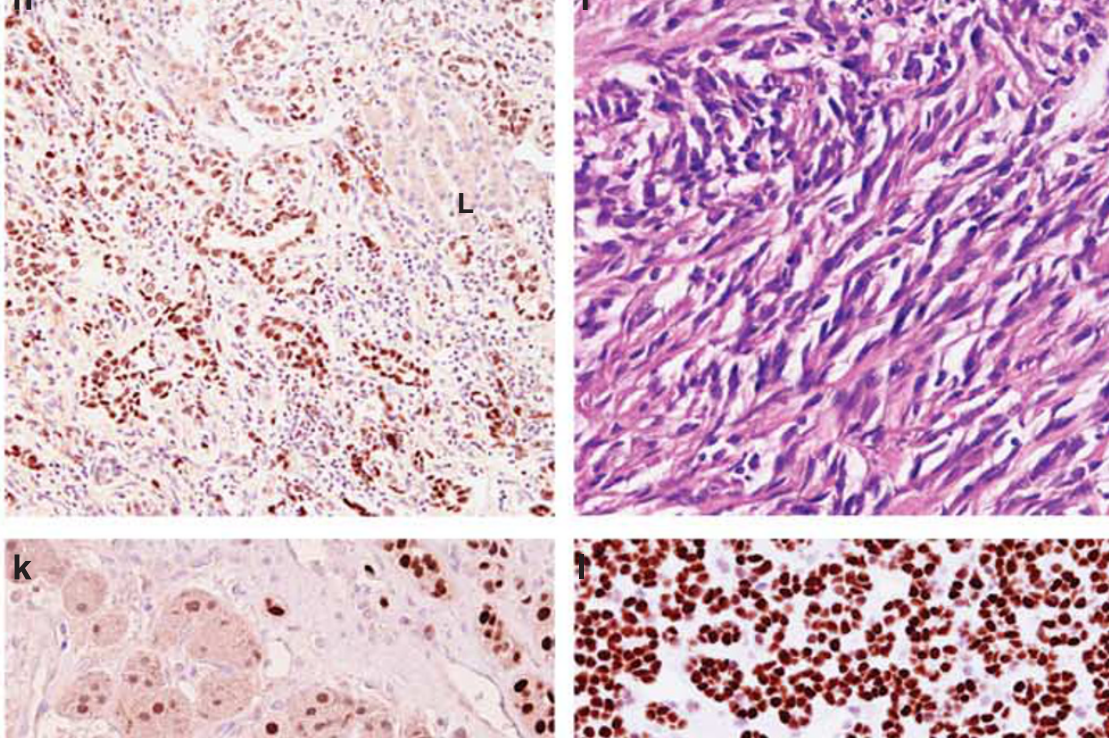

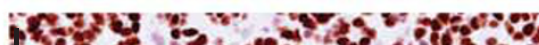

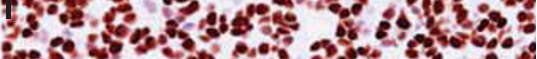
Es ${ }^{2}$.

of

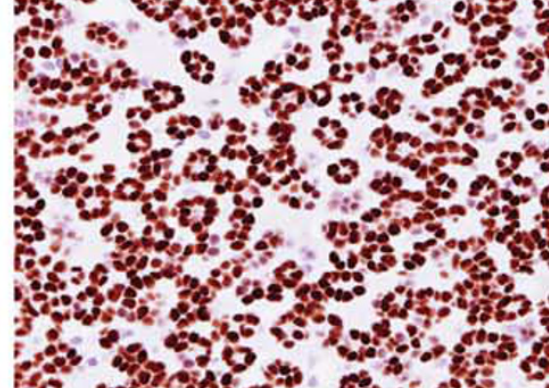


epithelial component of 4 of $4 \quad(100 \%)$ mixed epithelial and stromal tumors, 4 of $4(100 \%)$ cystic nephromas, and 8 of $13(61 \%)$ oncocytomas. In general, the staining intensity was stronger and the extent was greater for clear cell and papillary renal cell carcinomas than for other types of renal cell carcinomas. The staining was more pronounced in tumors with lower nuclear grades. The extent of staining ranged from a few cells to virtually all tumor cells, with staining of $>50 \%$ of tumor cells in most of the cases. PAX 8 was not expressed by any of the four renal cell carcinomas with rhabdoid features. It was not seen in any urothelial neoplasm or angiomyolipoma.

Of 247 (93\%) neoplasms of Müllerian origin, including those from the ovary, uterus, peritoneum, and fallopian tube, 238 showed PAX 8 staining. The staining is nearly universal (95-100\%) for serous, endometrioid, and clear cell types (Figure 3e-g), but was less frequent for mucinous tumors $(40 \%)$ and other types (urothelial, squamous, and undifferentiated) (66\%). In positive cases, staining was uniformly strong and involved most cells in $>75 \%$ of cases.

All 65 follicular and papillary thyroid neoplasms demonstrated positive staining for PAX 8 in virtually $100 \%$ of tumor cells (Figure $3 i$ and $j$ ).

Other tumor types that expressed PAX 8 included lymphomas of both small and large cell types (17/17 cases) and nephrogenic adenoma (8/8 cases) (Figure $3 \mathrm{k})$. PAX 8 was noted in 10 of $16(62 \%)$ parathyroid hyperplasia/adenomas and in 6 of 17 (35\%) welldifferentiated neuroendocrine tumors of the pancreas, but the stain was weaker and often focal compared with other tumor types.

All other 400 benign and malignant neoplasms were negative.

\section{Metastatic Neoplasms}

PAX 8 expression was noted in 245 of 496 (49\%) metastatic tumors, in patterns conforming to those of their corresponding primary neoplasms (Table 3 and Figure 4a-1).

PAX 8 was noted in 93, 100, and $80 \%$ of metastatic clear cell, papillary, and collecting duct renal cell carcinomas, respectively, regardless of the organ of involvement (Figure 4a-e). Although primary renal cell carcinomas with rhabdoid features were uniformly negative, two metastases with rhabdoid features were studied and both were positive. Only one metastatic chromophobe renal cell carcinoma was found (lung) and it was positive. In contrast to primary renal sarcomatoid renal cell carcinomas, PAX 8 was not seen in any of the six metastatic sarcomatoid renal cell carcinomas. As in primary renal cell carcinomas, the staining was strong $(3+)$ and involved $>50 \%$ of tumor cells in more than half of the metastatic neoplasms.

Overall, 57 out of $63(90 \%)$ metastatic tumors of Müllerian origin were positive for PAX 8 (100, 100, 95 , and $50 \%$ for endometrioid, clear cell, serous, and undifferentiated tumors, respectively) (Figure $4 \mathrm{i}$ and $\mathrm{j}$ ). The staining was often diffuse with involvement of most tumor cells. In addition, strong and diffuse positive immunoreactivity for PAX 8 was detected in all 13 cytology specimens of Müllerian carcinoma, including specimens with scant cellularity (Figure $4 \mathrm{k}$ and $\mathrm{l}$ ).

PAX 8 was expressed by virtually all tumor cells in each of the six metastatic thyroid papillary carcinomas, but was not seen in any metastatic medullary carcinomas (Figure $3 \mathrm{i}$ and $\mathrm{j}$ ).

In all, 1 out of 9 metastatic neuroendocrine tumors (pancreas to lymph node), and 1 out of 15 metastatic small cell carcinomas (lung to liver) were positive, with weak staining of $<5 \%$ tumor cells (Figure $3 \mathrm{k}$ and 1 ).

PAX 8 was not expressed by the remaining 251 metastatic tumors (Figure $4 \mathrm{~g}$ and $\mathrm{h}$ ).

\section{Discussion}

This comprehensive study shows that PAX 8 is constantly expressed in normal tissues from a limited number of organs or tissues including renal tubules, Müllerian and wolffian-related organs, thyroid follicular cells, and a subset of lymphocytes. We have also further confirmed that PAX 8 is also a sensitive and specific marker for both primary and metastatic tumors derived from these organs/tissues. These findings are in keeping with the fact that PAX 8 controls the embryonic development of these organs.

\section{PAX 8 in Embryogenesis}

PAX 8 is a cell lineage-restricted transcription factor, with expression limited to the primordial tissues of

Figure 2 Renal neoplasms. (a) Clear cell renal cell carcinoma characterized by solid aggregations of tumor cells with a clear cytoplasm. There is diffuse PAX 8 nuclear expression. (b) Papillary renal cell carcinoma with diffuse PAX 8 expression in papillary structures. (c) Mixed epithelial and stromal tumors characterized by tubular or papilary structures against abundant stroma. Diffuse PAX 8 expression is limited to the epithelial component. (d) A chromophobe renal cell carcinoma characterized by reticulated, eosinophilic, and mixed cells. (e) Diffuse nuclear PAX 8 expression in this chromophobe renal cell carcinoma. (f) Another case of chromophobe renal cell carcinoma with focal nuclear staining. Strong PAX 8 expression in the adjacent atrophic renal tubules (lower left). (g) Collecting duct renal cell carcinoma with solid or tubular structures set against an abundant desmoplastic stroma. (h) Diffuse PAX 8 expression in tumor cells of the same case as in panel g. The tumor invade liver (L), which is negative for PAX 8. (i) Sarcomatoid renal cell carcinoma chracterized by abundant atypical spindled cells. (j) Strong PAX 8 expression in the same tumor in the consecutive tissue section. (k) Oncocytoma with focal nuclear staining and weak nonspecific cytoplasmic staining. Strong nuclear stain in the adjacent renal atrophic tubules (upper left). (l) Metanephric adenoma characterized by aggregations of microtubules, with strong and diffuse PAX 8 expression ( $\times 400$ for panels $\mathrm{g}$ and $\mathbf{i} ; \times 200$ for all other panels). 
the thyroid, ${ }^{4}$ wolffian (mesonephric) ducts, and Müllerian ducts. ${ }^{6,9}$ During organogenesis, these primordial structures give rise to the thyroid and urogenital organs, including the kidney, ureter, seminal vesicles, vas deferens, uterus, and fallopian tubes, under the partial control of PAX $8^{6,9}$

Together with PAX 2, PAX 8 has a crucial role in the embryonic development of the kidney., ${ }^{4,6-9}$
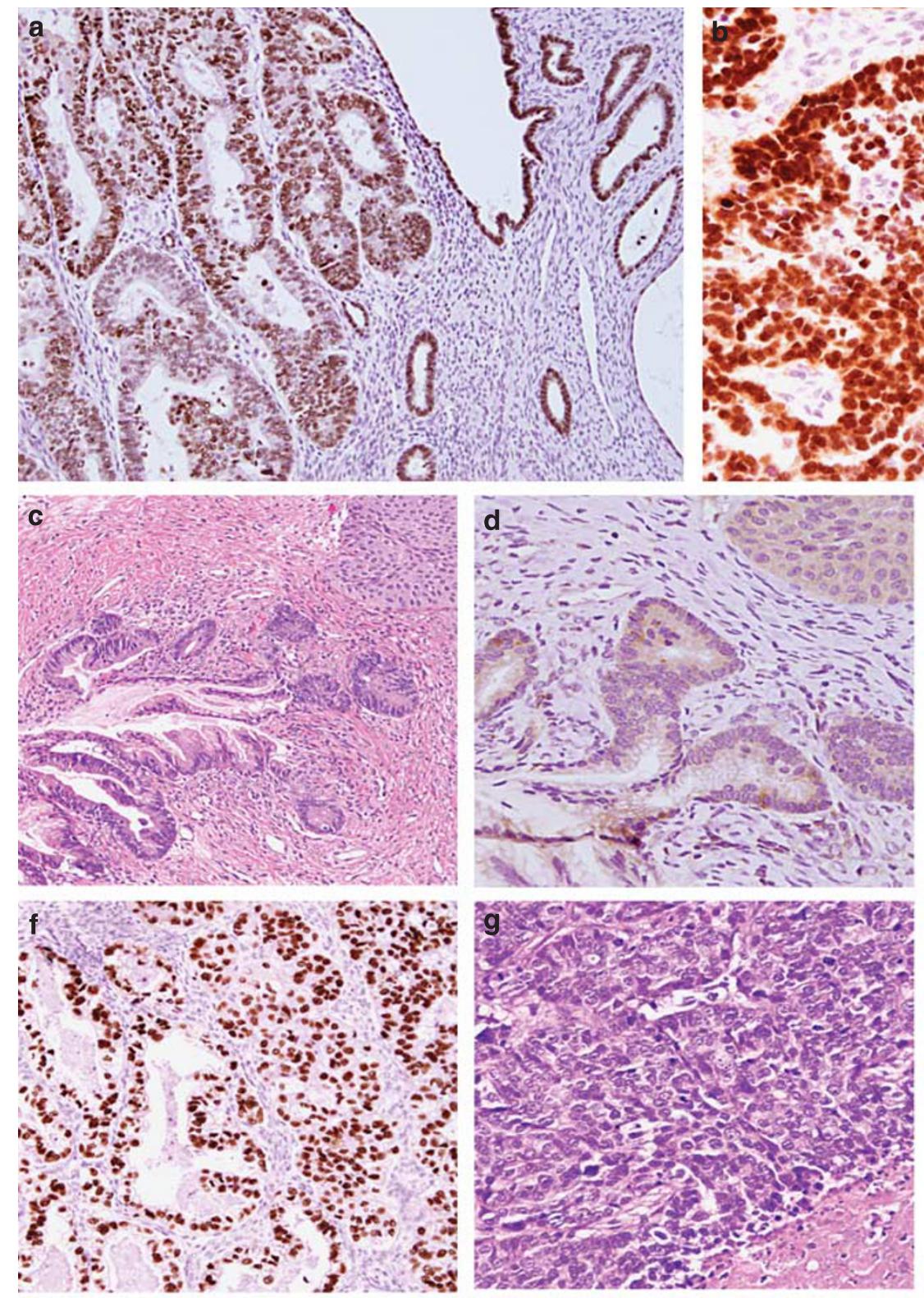
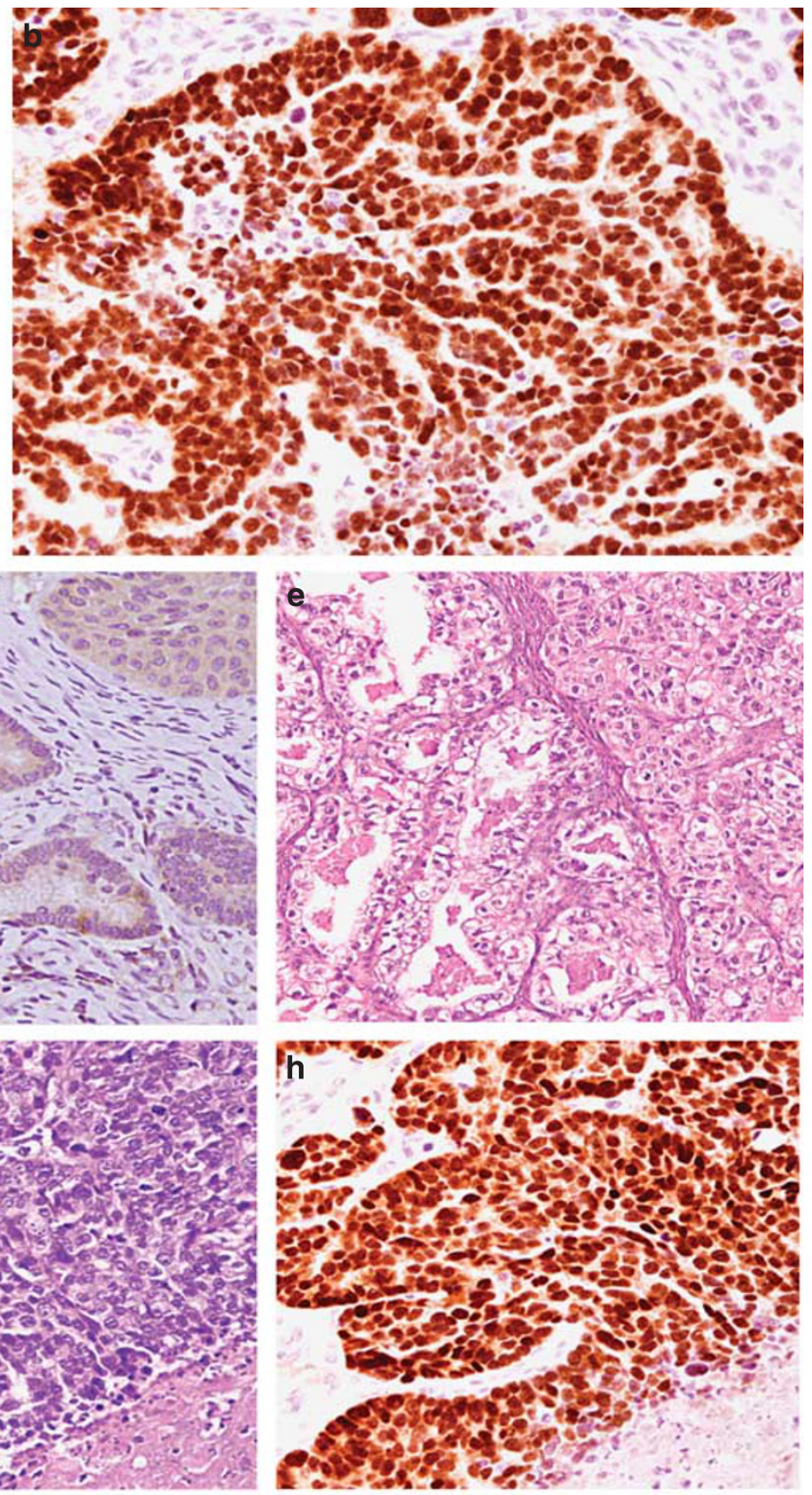
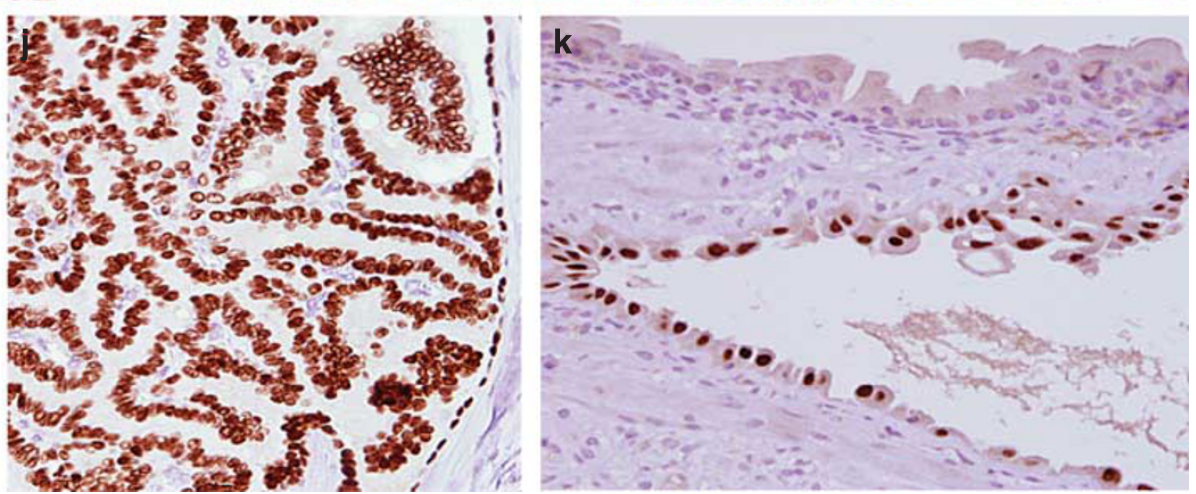
During nephrogenesis, PAX 8, together with PAX 2, is expressed very early in the renal blastema and later in collecting duct cells, and all progenitor epithelial cells of the developing nephron. They promote mesenchymal cell proliferation and apoptosis, and mesenchymal-epithelial transformation, with formation of immature renal tubules and glomeruli. ${ }^{21-24}$ Deletion of both $P A X 8$ and $P A X 2$ genes prevents generation of the mesonephric (wolffian) duct and subsequent formation of all three embryonic kidneys (pronephros, mesonephros, and metanephros). ${ }^{6,9}$ However, inactivation of the $P A X 8$ gene alone does not result in any kidney malformation..$^{8,9}$

PAX 8 is known to have a pivotal role in postnatal development of the Müllerian duct into organs of the female genital tract. ${ }^{25}$ Although PAX 8 expression is noted throughout the entire Müllerian duct, deletion of the $P A X 8$ gene results in a lack of endometrium, poor development of the myometrium, but normal formation of the fallopian tubes, cervix, and vagina, suggesting a complementary or compensatory role of other transcription factors, including PAX 2, in Müllerian organogenesis. ${ }^{18,25}$

PAX 8 is crucial for thyroid gland organogenesis together with thyroid transcription factor-1 and -2 . It may also mediate neoplastic transformation as ${ }^{15}$ $P A X$ 8-PPAR $\gamma$ rearrangement occurs in $20-30 \%$ of follicular thyroid carcinomas. ${ }^{12-15}$

PAX 8, together with PAX 2 and PAX 5, controls lymphoid genesis, especially the maturation of $B$ cells. ${ }^{26}$

\section{PAX 8 in Normal/Reactive Tissues}

Observations on PAX 8 expression in normal/ reactive tissues are limited. Tong et $a l^{16,17}$ and Bowen et $a l^{18}$ in studies of a limited number of cases showed PAX 8 expression in the nuclei of thyroid follicular cells, renal tubular epithelial cells, and epithelial cells of the fallopian tubes, endometrial glands, epididymis, vas deferens, and seminal vesicles, but not in epithelial cells of the breast, lung, esophagus, stomach, colon, pancreas, and mesothelium. Our comprehensive study corroborates and expands these observations. We found that PAX 8 expression is progressively attenuated along with renal maturation and is seen only focally in parietal epithelial cells and collecting ducts in the normal adult kidney. However, atrophic renal tubules, regardless of etiology and nephronic segment of origin strongly express PAX 8 (Figure 1b). These atrophic tubules, routinely seen at the periphery of most space-occupying renal lesions including renal cell carcinomas, should not be confused with neoplastic cells, which often express PAX 2 as well. ${ }^{27}$ The significance of this neoexpression is not clear, but it may be related to a known function of PAX 8 to promote the proliferation and repair of renal tubular cells. Although Tong et $a l^{16}$ described focal staining of renal pelvic urothelial cells, we have not observed PAX 8 expression in 27 samples of the urothelium from various locations.

Our study showed a constant, strong, and diffuse PAX 8 expression in epithelial cells of the mature endocervix and endometrium. Considering the general principle that a transcription factor tends to be strongly expressed during organogenesis and that this expression becomes much attenuated along with maturation, the observed PAX 8 expression in the mature Müllerian organs is surprising. However, these observations suggest that PAX 8 is pivotal not only for embryogenesis but also for homeostasis of the mature tissue. We have also noted that benign lesions related to the Müllerian epithelium such as the endometrial polyp, ovarian epithelial inclusion cyst, and endometriosis, adenomyosis, endosalpingiosis, paraovarian Müllerian embryonic rests, and paratubal epithelial cysts constantly express PAX 8, whereas stromal cells of these organs are uniformly negative. This discrepancy implicates an exquisite epithelium-limited embryogenetic control mediated by PAX 8 . We also confirm the interesting observation originally made by Bowen et $a l^{18}$ that in the tubal epithelium, basal and secretory cells are positive but ciliated cells are uniformly negative (Figure 1e). This discrepancy may be related to the observation that ciliated cells are terminally differentiated non-proliferating cells, which are derived from proliferation and maturation of other tubal epithelial cells, and PAX 8 expression may be important in this process. The ovarian surface epithelium was uniformly negative in the study by Bowen et al, but positive in $62 \%$ of our cases. The pelvic peritoneal surface cells including ovarian surface cells may maintain a dynamic balance between differentiation toward mesothelial cells, which are uniformly negative for $\operatorname{PAX} 8$, and

\footnotetext{
Figure 3 Other neoplasms. (a) Endometrioid carcinoma of the uterus characterized by densely packed glands, contrasting with the adjacent endometrium. There is diffuse PAX 8 staining of both components. (b) Serous carcinoma of the ovary, characterized by connecting strands or papillae of tumor cells. There is strong expression of PAX 8. (c) Mucinous borderline tumor of the ovary with an adjacent Brenner tumor component (upper left). (d) There is no staining for either component in the consecutive tissue section. (e) Clear cell carcinoma of the ovary with tubular and solid components, both of which are populated by tumor cells with a clear cytoplasm and atypical nuclei. (f) Diffuse PAX 8 staining in the consecutive tissue section. (g) Undifferentiated carcinoma of the omentum, with solid aggregations of highly atypical cells. (h) Diffuse and strong staining in tumor cells in the consecutive tissue section. (i) Papillary thyroid carcinoma with papillary fronds lined by tumor cells with nuclear clearing and grooves. (j) Diffuse and strong PAX 8 staining in the consecutive tissue section. (k) Nephrogenic adenoma of the bladder, with a tubular structure lined by a single layer of cells with strong PAX 8 nuclear staining. The overlying urothelium is negative $(\times 200$ for all panels).
} 

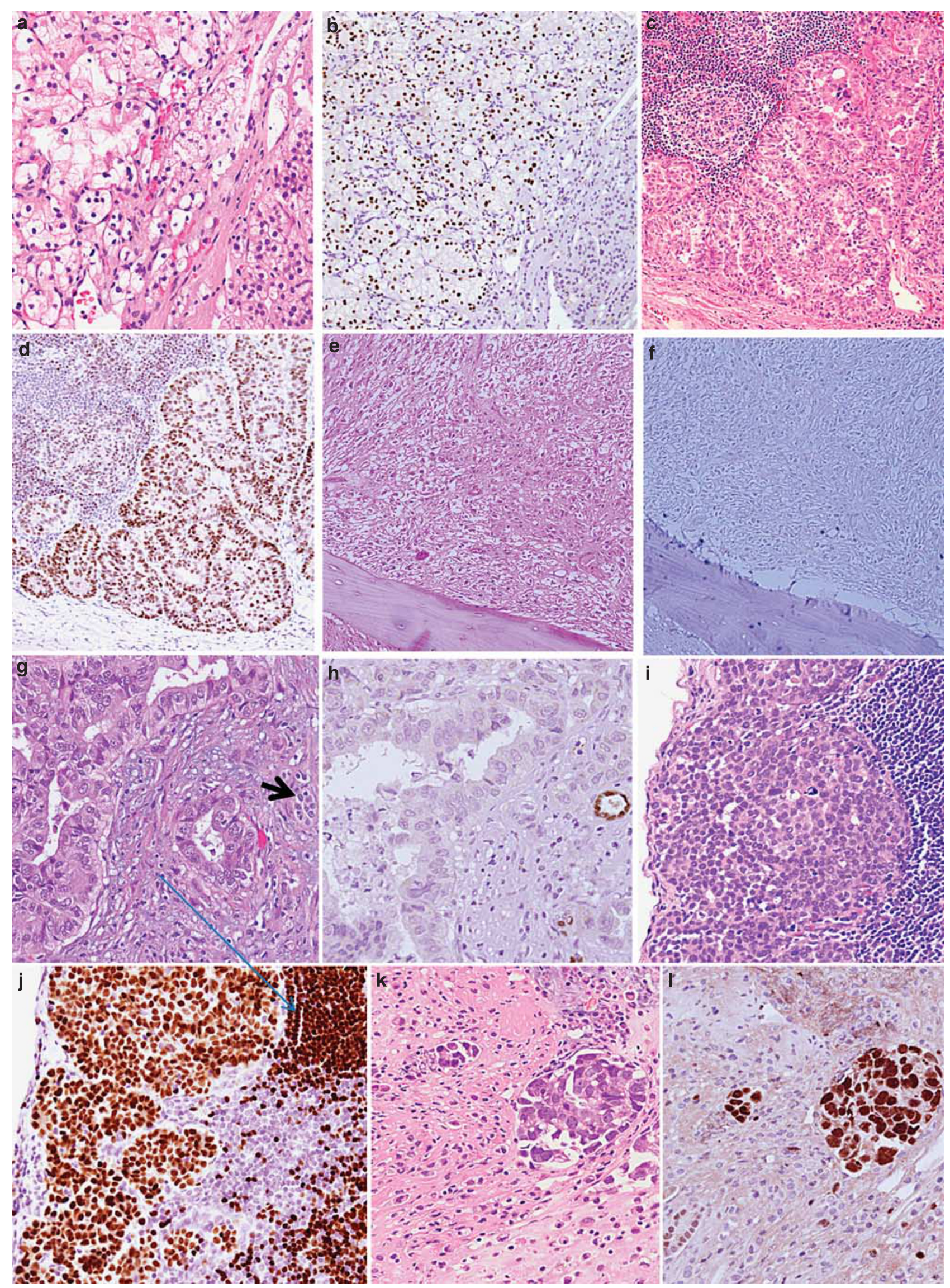
Müllerian cells, which constantly express PAX 8. This balance may explain the variable patterns of PAX 8 expression in ovarian surface epithelial cells.

Constant strong and diffuse PAX 8 staining was also noted in the epithelium of seminal vesicles, epididymis, testicular efferent ducts, but not in the urothelium, germ cells, Leydig cells, Sertoli cells, or the prostatic epithelium. These distinctive patterns are probably related to the observation that the mesonephric (wolffian) duct, partially under control of PAX 8 together with PAX 2, gives rise to the male genital outflow tract, ${ }^{8,9}$ whereas the renal pelvis, ureter, testis, and prostate are of different embryologic origin and are not developmentally related to PAX 8 and PAX 2..$^{8,9,21}$ These observations indicate a possible utility of PAX 8 in differential diagnosis of prostate cancer from seminal vesicle tissues, urothelial carcinomas, or germ cell carcinomas.

A sub-population of lymphocytes in benign lymphoid organs, probably B cells, constantly expresses PAX 8. Such an expression was also regularly noted in lymphoid cells associated with tumors and often served as a built-in control for PAX 8 staining.

Although the normal bile duct epithelium was uniformly negative, regenerative bile duct cells were stained in $11 \%$ of 35 cases. This implies a role of PAX 8 in bile duct regeneration. In this aspect, we have noted that all 16 cases of bile duct neoplasms were negative for PAX 8.

The current study shows PAX 8 expression in parathyroid parenchymal cells and pancreatic islet cells. Although the staining is focal and involves only some of the tested tissue samples, our findings do confirm the original observations by Tong et al ${ }^{16}$ and Long et $a{ }^{28}$ respectively. This pattern of expression is surprising as PAX 8 has not been known to control the organogenesis of parathyroid or pancreatic islets. However, it does have diagnostic implications, as a subset of parathyroid or islet cell neoplasms also express PAX 8 (see below).

\section{PAX 8 in Primary Tumors}

The rather limited cell/tissue-specific expression of PAX 8 and the capacity to immunolocalize this transcription factor in routinely processed tissues have promoted the use of PAX 8 as a diagnostic tumor marker. Previous studies have shown that PAX 8 was noted in most renal cell carcinomas
$(89 \%),{ }^{16}$ most ovarian carcinomas (64-100\%), ${ }^{18-20}$ and in all nephrogenic adenomas, ${ }^{17}$ but staining features in relation to pattern, extent, histological types, or differentiation levels were not detailed.

The current study showed that the majority (71$100 \%$ ) of renal neoplasms of renal tubular cell origin, regardless of histological type and putative nephronic segment of origin, express PAX 8, in keeping with the observation that PAX 8 is limited to the normal collecting duct, but is strongly expressed throughout the atrophic nephronic segment. In fact, metanephric adenoma and Wilms' tumor, which belong to the family of renal metanephric neoplasms characterized by an 'embryonic' phenotype, display a level of PAX 8 expression significantly beyond the already strong staining of other renal cell carcinoma types such as clear cell or papillary (Figure 2l), reflecting the pronounced PAX 8 expression during renal embryogenesis. Even sarcomatoid renal cell carcinoma, which is almost always negative for other traditional renal markers such as the renal cell carcinoma marker, CD10, or kidney-specific cadherin, was positive in 4 of 9 cases $(44 \%)$ in our study, in concordance with a rate of $71 \%$ as reported by Tong et al. ${ }^{16}$ The staining and extent of staining tend to depend on tumor types and differentiation level, thus accounting for usually less expression in chromophobe renal cell carcinoma and oncocytoma, less expression in less-differentiated areas of tumor of any histological type, and absence of staining in all tumors with rhabdoid features. Renal tumor tissues of mesenchymal origin including angiomyolipoma, renal medullary fibroma, or spindle cells of mixed epithelial and stromal tumors were uniformly negative.

In all, 33 urothelial neoplasms (13 from the renal pelvis and 20 from the urinary bladder) and the adjacent urothelium in our study were uniformly negative for PAX 8. In contrast, Pellizzari et al ${ }^{29}$ reported positive PAX 8 staining in 13 of 13 cases of urinary bladder urothelial carcinomas, but not in the normal urothelium. Tong et al noted positive staining in 4 of $17(23 \%)$ renal pelvic urothelial neoplasms and focal staining of the renal pelvic urothelium, but not in the bladder urothelium or 43 bladder urothelial neoplasms. ${ }^{29}$ The explanation for this discrepancy is not obvious, but may be of technical nature including the different types of antibodies used, which are all polyclonal and of different sources. In this aspect, it is noted that the

\footnotetext{
Figure 4 Metastatic tumors. (a) Clear cell renal cell carcinoma metastatic to the adrenal gland (lower left). (b) Diffuse PAX 8 staining of tumor cells, but adrenal cortical cells (lower left) are negative. (c) Papillary renal cell carcinoma metastatic to a lymph node. (d) Tumor cells are strongly positive for PAX 8 in a consecutive tissue section. There is also focal staining of lymphoid cells. (e) Sarcomatoid renal cell carcinoma metastatic to the bone. (f) The tumor cells are negative for PAX 8. (g) Colonic adenocarcinoma metastatic to the kidney. An atrophic renal tubular profile is noted (arrows). (h) The carcinoma cells are negative, contrasting with strong staining for the renal tubular cells (left). (i) Serous carcinoma metastatic to a lymph node. (j) The tumor cells are strongly positive in the consecutive tissue section. There is also staining of the lymphoid cells (left). (k) Serous carcinoma in the cell-block section of ascitic fluid. There are non-neoplastic cells, probably mesothelial cells, in the background. (l) The tumor cells are strongly positive for PAX 8, but other cells in the background are negative. ( $\times 400$ for panels $\mathbf{g}, \mathbf{h}$, and $\mathbf{i} ; \times 200$ for other panels).
} 
renal pelvis and the lower urinary tract are embryologically derived from the urogenital sinus, in contrast to the wolffian origin of the kidney. Furthermore, the PAX family of transcription factor is not known to express in the urogenital sinus or control its embryonic development.

Nonaka et al in a tissue microarray noted PAX 8 staining in 96,90 , and $100 \%$ of 81 serous, 18 endometriod, and 10 clear cell carcinomas, respectively, of the ovary. ${ }^{19}$ Laury et $a l^{20}$ noted PAX 8 expression in virtually every case of serous ovarian neoplasms, regardless of grade. Our study that mostly used whole-tissue sections from a large number of cases spanning the whole histological spectrum of Müllerian tumors supports these observations. It further indicates that the organ of origin, ie, the ovary, uterus, and omentum, does not impact staining, but mucinous, squamous, undifferentiated, or Brenner-type tumors are associated with a marked attenuation of PAX 8 expression.

PAX 8 is crucial for thyroid development. Fusion of the $P A X 8$ gene and the $P P A R \gamma$ gene has a role in the development of follicular neoplasms, leading to several studies to immunolocalize the PPAR $\gamma$ protein alone or the PAX 8-PPAR $\gamma$ fusion protein as a marker for follicular neoplasms., ${ }^{3,42-14}$ Yet, a systematic study of the PAX 8 protein alone in thyroid neoplasm is not available. Our study shows a diffuse PAX 8 staining of each of the 65 follicular or papillary neoplasms, as was the adjacent benign follicular cells, but always negative in medullary carcinoma. These observations clearly indicate PAX 8 as a sensitive marker for thyroid differentiation.

All 17 lymphomas in our study, regardless of histological types, were diffusely positive for PAX 8.

Aside from the frequent PAX 8 expression in neoplasms from organs, the embryonic development of which depends at least partly on PAX 8, this molecule is expressed in all nephrogenic adenomas, as shown in the study by Tong et al and in the current study, and by the seven cases of clear cell carcinoma of the bladder as reported by Tong et $a{ }^{17}{ }^{17}$ In this aspect, the constant PAX 8 expression in nephrogenic adenoma, a tumor of uncertain histogenesis until recently, supports a renal tubular cell-like differentiation, as further supported by other genotypic and immunological findings.

Although PAX 8 is well accepted as a sensitive marker for tumors of renal, Müllerian, thyroid, or lymphoid origin, whether it is also specific, ie, whether other tumors also express PAX 8 is not well established. Laury et $a l^{20}$ noted that PAX 8 is not expressed in 24 pleural malignant mesotheliomas, but focal weak staining was seen in 2 of 23 peritoneal malignant mesotheliomas, an additional hint for possible dual mesothelial/Müllerian differentiation peculiar for peritoneal surface cells. Our comprehensive study shows weak focal staining in
$42 \%$ of parathyroid hyperplasia/adenomas. Weak focal staining was also noted in 6 of 17 (35\%) welldifferentiated pancreatic neuroendocrine tumors. However, the frequency and the extent of staining of this tumor type in our study is less than those reported by Long et $a{ }^{28}{ }^{28}$ who described strong and diffuse nuclear staining in 42 of $63(66 \%)$ and in 21 of $93(22 \%)$ well-differentiated neuroendocrine tumors of the pancreas and of organs other than the pancreas, respectively. The reason for this discrepancy is not clear, but at least may be related to the polyclonal nature of the antibodies, although from the same commercial source, used in both studies, and/or other technical considerations, including methods of antigen retrieval. However, all other 400 neoplasms from diverse organs were negative.

The collective data indicate that PAX 8 is a very sensitive and specific marker for tumor of renal, Müllerian, and thyroid origins.

\section{PAX 8 Expression in Metastatic Neoplasms}

PAX 8 expression in the metastatic context has not been systematically evaluated. Yet, this matter is important for several reasons. Determination of cellular lineage, an interesting but often diagnostically irrelevant task in the study of primary neoplasms, becomes critical for metastatic tumors, especially for those of unknown primary tumors or for those identified against the background of multiple primary tumors. Furthermore, the antigenic profiles of metastases may be different from those of their corresponding primary tumors. For example, the renal cell carcinoma marker, a sensitive marker for renal cell carcinoma, was noted in $80 \%$ of primary renal cell carcinomas but was expressed only in less than half of metastatic renal cell carcinomas with a marked decrease in the percentage of positive cells. ${ }^{30}$ The current study showed that the sensitivity of PAX 8 as a tumor marker is comparable for metastatic and primary tumors. The overall PAX 8 expression for metastatic renal cell carcinomas compared with that of their primary tumors was 88 vs $89 \%$, with a similar staining extent $(>50 \%$ of tumor cells in $>50 \%$ of cases). For collecting duct renal cell carcinoma, a type of renal cell carcinoma well known for a lack of expression for many other 'renal-specific' markers, the rates of PAX 8 expression in primary and metastatic tumor were 71 and $80 \%$, respectively. These findings further indicate a primary-metastatic concordance for PAX 8 expression. On the other hand, PAX 8 was not seen in any metastatic sarcomatoid renal cell carcinoma in our study, further confirming that a specific marker for this aggressive variant of renal cell carcinoma remains elusive. PAX 8 is equally sensitive for metastatic $(90 \%)$ and primary tumors $(96 \%)$ of Müllerian origin. This study also demonstrates that PAX 8 
maintains its diagnostic specificity in the metastatic context. Thus, out of 251 metastatic tumors other than those of renal, Müllerian, or thyroid origin, only 1 lung small cell carcinoma and 1 pancreatic well-differentiated neuroendocrine, both metastatic to lymph nodes, were focally and weakly positive for PAX 8, in spite of a negative staining for their primary tumors. In this aspect, Long et $a l^{28}$ described PAX 8 expression in 9 of $18(50 \%)$ and in 0 of $16(0 \%)$ liver metastases of pancreatic and ileal well-differentiated neuroendocrine tumors, respectively.

In summary, this comprehensive study indicates that PAX 8 can be successfully identified in routinely processed tissue samples, in spite of the variable antigenic preservation in these samples. PAX 8 expression in non-neoplastic mature tissues is limited mostly to organs the embryonic development of which depends on this transcription factor, including the kidney, Müllerian organs, and thyroid; sporadic 'aberrant' expression may be observed in parathyroid and pancreatic islets. This tissue/cellspecific expression is maintained during both neoplastic transformation and metastasis. PAX 8 is a sensitive and specific marker for tumors of the thyroid, renal, and Müllerian organs in their primary and metastatic sites.

\section{Disclosure/conflict of interest}

The authors declare no conflict of interest.

\section{References}

1 Mansouri A, Hallonet M, Gruss P. PAX genes and their roles in cell differentiation and development. Curr Opin Cell Biol 1996;8:851-857.

2 Dahl E, Koseki H, Balling R. PAX genes and organogenesis. Bioassays 1997;9:755-765.

3 Plachov D, Chowdhury K, Walther C, et al. PAX 8, a murine paired box gene expressed in the developing excretory system and thyroid gland. Development 1990;110:643-651.

4 Poleev A, Fickenscher H, Mundlos S, et al. PAX 8, a human paired box gene: isolation and expression in developing thyroid, kidney and Wilms' tumors. Development 1992;116:611-623.

5 Mansouri A, Chowdhury K, Gruss P. Follicular cells of the thyroid gland require PAX 8 gene function. Nat Genet 1998;19:87-90.

6 Bouchard M, Souabni A, Mandler M, et al. Nephric lineage specification by PAX-2 and PAX 8. Genes Dev 2002;16:2958-2970.

7 Bouchard M. Transcriptional control of kidney development. Differentiation 2004;72:295-306.

8 Grote D, Souabni A, Busslinger M, et al. PAX 2/8regulated Gata 3 expression is necessary for morphogenesis and guidance of the nephric duct in the developing kidney. Development 2006;133:53-61.

9 Narlis M, Grote D, Gaitan Y, et al. PAX-2 and PAX 8 regulate branching morphogenesis and nephron differentiation in the developing kidney. J Am Soc Nephrol 2007;18:1121-1129.

10 Maulbecker CC, Gruss P. The oncogenic potential of Pax genes. EMBO J 1993;12:2361-2367.

11 Ozcan A, Ge Y, Rust M, et al. PAX 8 as a marker for renal, Müllerian, and thyroid differentiation. A comprehensive study. Mod Pathol 2010;23(Supplement 1):437A.

12 Kroll TG, Sarraf P, Pecciarini L, et al. PAX8-PPARgamma1 fusion oncogene in human thyroid carcinoma. Science 2000;289:1357-1360.

13 Cheung L, Messina M, Gill A, et al. RAS point mutations and PAX8-PPAR gamma rearrangement in thyroid tumors: evidence for distinct molecular pathways in thyroid follicular carcinoma. J Clin Endocrinol Metab 2003;88:2318-2326.

14 Clifton-Bligh R, Robinson BG. Detection of the PAX8PPAR gamma fusion oncogene in both follicular thyroid carcinomas and adenomas. J Clin Endocrinol Metab 2003;88:354-357.

15 Nonaka D, Tang Y, Chiriboga L, et al. Diagnostic utility of thyroid transcription factors PAX 8 and TTF-2 (FoxE1) in thyroid epithelial neoplasms. Mod Pathol 2008;21:192-200.

16 Tong GX, Yu WM, Beaubier NT, et al. Expression of PAX 8 in normal and neoplastic renal tissues: an immunohistochemical study. Mod Pathol 2009;22: 1218-1227.

17 Tong GX, Weeden EM, Hamele-Bena D, et al. Expression of PAX 8 in nephrogenic adenoma and clear cell adenocarcinoma of the lower urinary tract: evidence of related histogenesis? Am J Surg Pathol 2008;32: 1380-1387.

18 Bowen NJ, Logani S, Dickerson EB, et al. Emerging roles for PAX 8 in ovarian cancer and endosalpingeal development. Gynecol Oncol 2007;104:331-337.

19 Nonaka D, Chiriboga L, Soslow RA. Expression of PAX 8 as a useful marker in distinguishing ovarian carcinomas from mammary carcinomas. Am J Surg Pathol 2008;32:1566-1571.

20 Laury AR, Hornick JL, Perets R, et al. PAX 8 reliably distinguishes ovarian serous tumors from malignant mesothelioma. Am J Surg Pathol 2010;34: 627-635.

21 Torres M, Gomex-Pardo E, Dressler GR, et al. PAX-2 controls multiple steps of urogenital development. Development 1995;121:4057-4065.

22 Dressler GR, Wilkinson JE, Rothenpieler UW, et al. Deregulation of PAX-2 expression in transgenic mice generates severe kidney abnormalities. Nature 1993;362:65-67.

23 Eccles MR. The role of PAX-2 in normal and abnormal development of the urinary tract. Pediatr Nephrol 1998;12:712-720.

24 Eccles MR, He S, Legge M, et al. PAX genes in development and disease: the role of PAX-2 in urogenital tract development. Int J Dev Biol 2002;46: $535-544$

25 Mittag J, Winterhager E, Bauer K, et al. Congenital hypothyroid female PAX8-deficient mice are infertile despite thyroid hormone replacement therapy. Endocrinology 2007;148:719-725.

26 Rothenberg EV, Pant R. Origins of lymphocyte developmental programs: transcription factor evidence. Semin Immunol 2004;16:227-238. 13.

27 Zhai QJ, Ozcan A, Hamilton C, et al. PAX-2 expression in non-neoplastic, primary neoplastic, and metastatic neoplastic tissue: a comprehensive immunohisto- 
chemical study. Appl Immunohistochem Mol Morphol 2010;18:323-332.

28 Long KB, Srivastana A, Hirsch MS, et al. PAX 8 expression in well-diffrentiated pancreatic endocrine tumors: correlation with clinicopathologic features and comparison with gastrointestinal and pulmonary carcinoid tumors. Am J Surg Pathol 2010;34:723-729.
29 Pellizzari L, Puppin C, Mariuzzi L, et al. PAX 8 expression in human bladder cancer. Oncol Rep 2006;16:1015-1020.

30 McGregor DK, Khurana KK, Cao C, et al. Diagnosing primary and metastatic renal cell carcinoma: the use of the monoclonal antibody 'renal cell carcinoma marker'. Am J Surg Pathol 2001;25:1485-1492. 